This item was submitted to Loughborough's Research Repository by the author.

Items in Figshare are protected by copyright, with all rights reserved, unless otherwise indicated.

\title{
What is good design in the eyes of older users?
}

PLEASE CITE THE PUBLISHED VERSION

http://www.springerlink.com/

PUBLISHER

(C) Springer

VERSION

AM (Accepted Manuscript)

LICENCE

CC BY-NC-ND 4.0

REPOSITORY RECORD

Goddard, N., and C.A. Nicolle. 2019. "What Is Good Design in the Eyes of Older Users?". figshare. https://hdl.handle.net/2134/9454. 
This item was submitted to Loughborough's Institutional Repository (https://dspace.lboro.ac.uk/) by the author and is made available under the following Creative Commons Licence conditions.

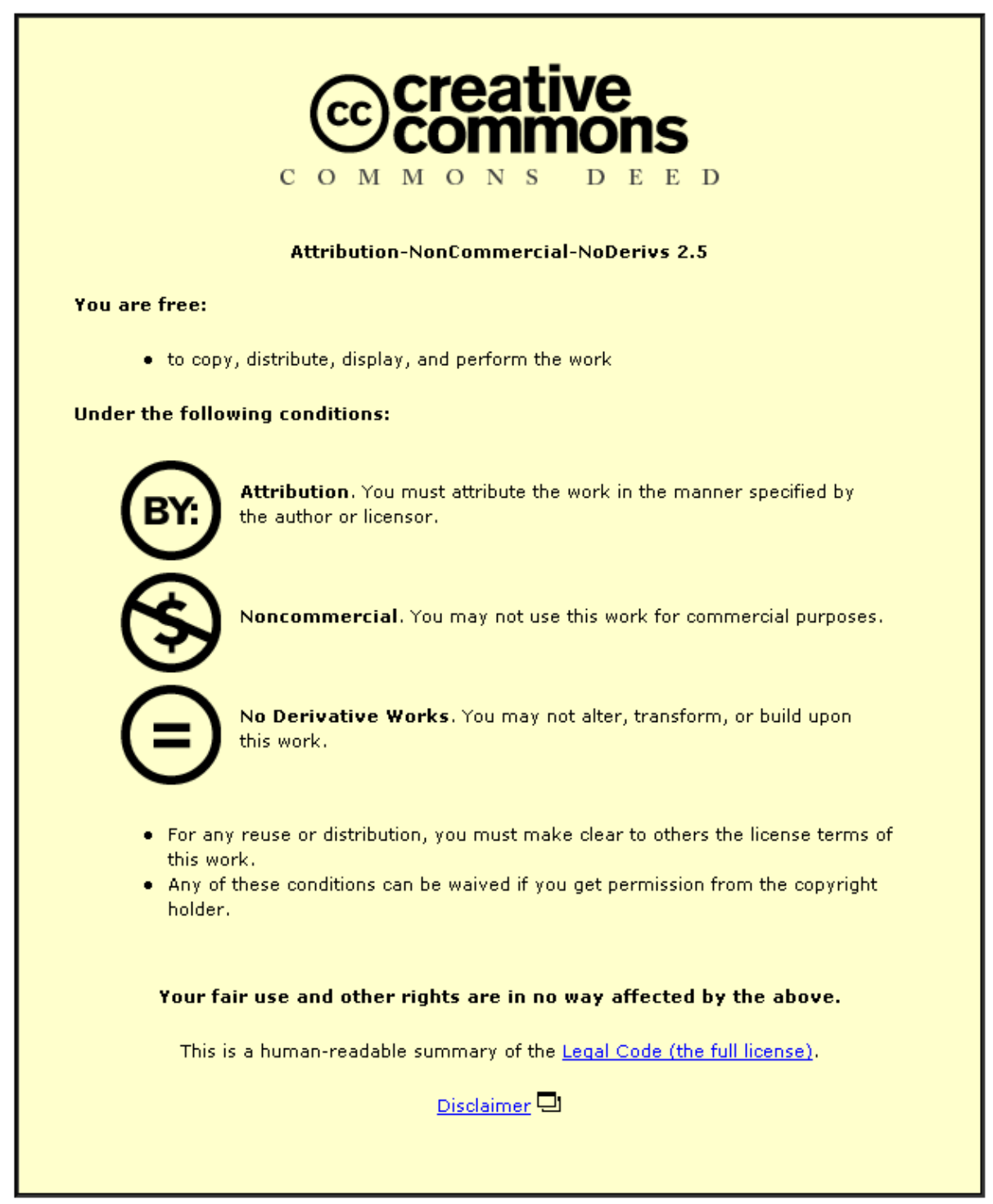

For the full text of this licence, please go to: http://creativecommons.org/licenses/by-nc-nd/2.5/ 


\title{
Chapter X
}

\section{What is Good Design in the Eyes of Older Users?}

\author{
N. Goddard and C. Nicolle
}

\section{X.1 Introduction}

With the population of older consumers increasing and with the recent changes in legislation and attitudes towards this group, there have been corresponding changes in product design practice and a growing attempt to adopt an inclusive design approach. This recognises that people can become excluded from using products, services or environments if the needs and capabilities of all potential users are not taken into account. The inclusive design approach has developed from collaborations between industry, designers and researchers. One major influence in this area is the $\mathrm{i} \sim$ design project, whose definition is simply that "inclusive design is better design" (EDC, 2011). The Inclusive Design Toolkit website, a key output from the i design project, states that a successful product must be "functional, usable, desirable and ultimately profitable" and that a key to good design is to reduce the demand on the user when capabilities decline with age or disability (EDC, 2011).

It is also important to consider more emotional aspects, such as social acceptability and whether the potential user would actually want to use or be seen using the product (Keates and Clarkson, 2003). Other authors also emphasise that whilst inclusive design research and practice to date have focused primarily on the physical accessibility and usability of products, a better understanding is required of people's emotional needs, such as social acceptability and desirability of products (Coleman et al, 2007; Lee, 2010). Similar views regarding the required shift in design focus are reflected in a number of other sources: the need to consider the less tangible human factors such as identity, emotion, delight and selfexpression (Cassim et al, 2007); simplicity, aesthetics, pleasure, personality, conspicuousness and fashion (Pullin, 2009); the product's visual appearance (Crilly et al, 2004); creating pleasurable experiences (Demirbilek and Sener, 2003; Jordan, 2000); and the importance of the emotional aspects of design for a successful product (Norman, 2004), as well as needs related to specific cognitive conditions (e.g. Baumers and Heylighen, 2010). 
However, knowledge about what is good design can only arise by cooperation between designers and the end users; designers themselves cannot always judge what is good without understanding the point of view of the users (Heylighen and Bianchin, 2010). Therefore, the objective of the current study was to take a usercentred approach to investigate what makes good product design in the eyes of older people themselves and how their criteria for good design compare with those considered by designers and researchers.

\section{X.2 Methods}

The first stage involved an ethnographic approach, combining semi-structured interviews and observation in people's homes, enabling an understanding of older users' individual opinions and use of everyday products in their natural environment. All procedures were approved by the University's Ethical Advisory Committee.

Participants were either emailed or handed (as per their preference) a preinterview questionnaire to complete and return prior to the start of the interview. The first part of the questionnaire collected personal background information to provide context for the interview and analysis. The second part explained a preinterview task: to think about one product they consider of good design and one product they consider of bad design. Whilst a detailed interview schedule was developed to enable a certain level of consistency of questioning across interviews, the interviews were semi-structured in order to provide flexibility to follow the lead of the participant and their own terminology, and also to follow up on any unexpected line of thinking.

To enable some degree of quantification of responses, a shuffle card exercise was introduced which required each participant to prioritise a set of 30 criteria, written on cards, by dividing them into three piles in terms of importance to them for good product design. An example of a 'most important' pile is shown below in Figure 1.

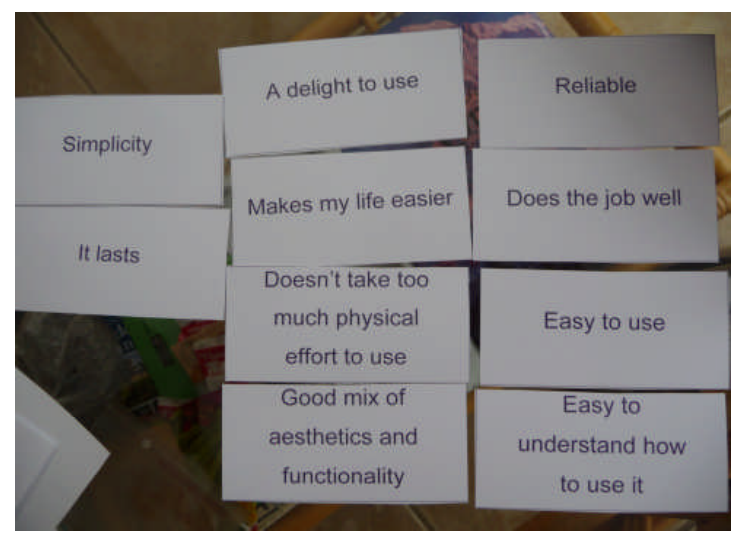

Figure 1: Shuffle card exercise to prioritise criteria 
During the interviews, participants were observed using the products and any difficulties encountered with them. The benefits of taking a more ethnographic approach were proven to be as follows: participants were able to demonstrate how they used products in their normal environment and the difficulties they experienced; participants' non-verbal cues could be observed to add understanding and context, e.g. laughing or tone of voice; and observation revealed gaps between what people said and what happened in reality.

Transcripts of all interviews were made in order to provide a complete and accurate record of the data collected and to enable structured analysis. An initial review of the transcripts was carried out to input to the design of the online questionnaire, hosted on SurveyMonkey ${ }^{\mathrm{TM}}$. This formed the second stage of the study and enabled a certain degree of validation of the stage one findings. The language used and the themes covered in the online questionnaire were based on both the interviewees' comments and themes from the literature review.

The data from the interviews and the online questionnaire were coded and analysed according to key themes, their source and frequency of occurrence, using the qualitative data analysis software NVivo.

\section{X.3 Results}

Thirteen interview sessions were conducted amongst people aged 65 or over, lasting between 45 and 90 minutes, including a mix of one-to-one interviews, paired interviews with couples and a mini group of three friends. This resulted in a total sample of 22 participants. During the interviews, participants were observed demonstrating the products and any difficulties encountered with them.

Details of the age, gender, living arrangements and impairments of the interview participants are summarised in Table 1.

Table 1: Interview participant details

\begin{tabular}{|l|l|l|l|}
\hline & Total & Male & Female \\
\hline Age & & & \\
\hline $65-74$ & 7 & 1 & 6 \\
\hline $75-84$ & 13 & 7 & 6 \\
\hline $85+$ & 2 & 1 & 1 \\
\hline & & & \\
\hline Living arrangements & & & \\
\hline Live alone & 7 & 2 & 5 \\
\hline Live with partner & 15 & 7 & 8 \\
\hline & & & \\
\hline $\begin{array}{l}\text { Impairments } \\
\text { (moderate or severe) }\end{array}$ & & & \\
\hline Vision & 10 & 4 & 6 \\
\hline Dexterity (arthritis) & 5 & 2 & 3 \\
\hline Mobility & 4 & 2 & 2 \\
\hline Multiple impairments & 8 & 4 & 4 \\
\hline
\end{tabular}


For the online questionnaire, a sample of older users was achieved by obtaining permission to post a link on a number of University of the Third Age (U3A) websites across the East Midlands. Seventy-two respondents completed the questionnaire, although only 54 answered the demographic questions at the end of the questionnaire (Table 2).

Table 2: Online respondents $(n=54$ out of 72$)$

\begin{tabular}{|l|l|}
\hline Total & $\mathbf{5 4}$ \\
\hline Male & 14 \\
\hline Female & 40 \\
\hline & \\
\hline Age & \\
\hline $55-64$ & 19 \\
\hline $65-74$ & 25 \\
\hline $75-84$ & 9 \\
\hline $85+$ & 1 \\
\hline
\end{tabular}

The key themes that emerged from analysis of the interview data and the responses to the online questionnaire were based on the frequency of responses and are summarised in Figure 2. High level themes, which were then broken down into finer categories, included the elements of good and bad design; elements in purchase decision; comments on aesthetics vs function; role of family, friends and other people; tricks, solutions and adaptations; and reactions to Good Grips products.

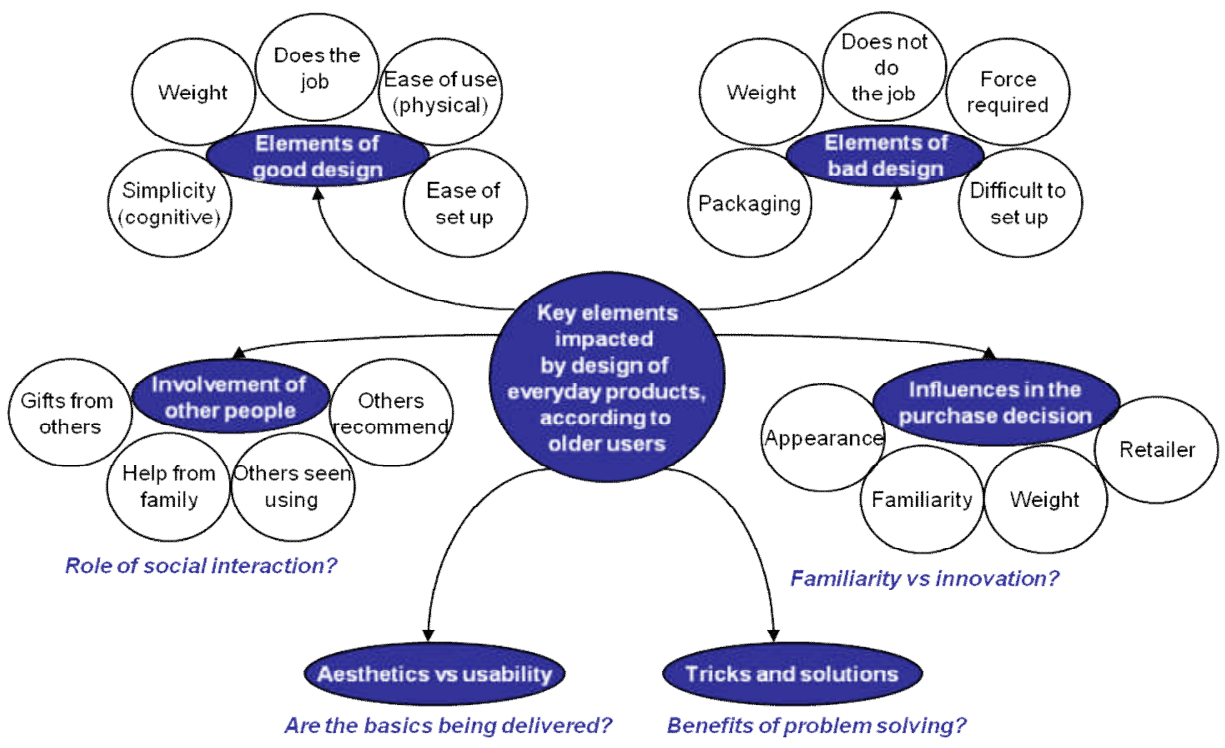

Figure 2: Key themes from the research 
The most important criteria for good design amongst older users in this study are that products are easy to use, they do the job they are supposed to well and are simple to understand. The most likely problems that older users experience with products, and which are therefore seen as elements of bad design, are difficulties getting into some types of packaging and the heavy weight of some products. These findings are not surprising; however, the section below discusses some interesting results which shed a new light on these issues.

\section{X.4 Discussion}

\section{X4.1 Aesthetics versus usability}

From detailed analysis of data from both the interviews and open-ended online questions, it would appear that many older people would prefer, ideally, to have products that were not just easy to use but also looked good - but importantly, only if usability has been delivered. This idea links to Maslow's hierarchy of needs (Maslow, 1987) which is often used to help understand consumers' requirements from products. According to this model, once the needs at the lower levels, e.g. safety and comfort, have been satisfied, emphasis can shift to needs at the higher levels, that is, towards the more emotional attributes of a product. Jordan adapted Maslow's model to a Human Factors perspective, creating a new three-level model with 'functionality' at the lowest level, 'usability' in the middle and 'pleasure' at the highest level (Jordan, 2000). Using this model to interpret the current results, users' basic needs of functionality (performs the tasks for which it is intended) and usability (easy to use) do not appear to be met. Many are experiencing difficulties and are therefore not able to progress to the higher levels to meet their emotional needs. If the more functional needs were being addressed successfully then the 'pleasure' needs, including looks, would become increasingly important.

The literature review revealed that several authors believe that the focus for design should shift to delivering fulfilment at the higher levels, for both users in general and older users (e.g., Lee, 2010; Crilly et al, 2004). However, the results from this study would indicate that product design may be leaving older users behind by not delivering successfully at the functional level for these groups. These results support the view that some designers may have become overly concerned with the aesthetics of product interfaces, resulting in problems being caused for people with impairments (Noonan, 2007).

\section{X4.2 Tricks and solutions for packaging problems}

The current study indicates that difficulties encountered in getting into different forms of packaging are not uncommon, and for most (but interestingly not all) people a source of irritation. In particular, it would appear that many people have problems using can and jar openers and with opening child-safe bottle tops. Difficulties and alternative solutions identified in the current study are very similar 
to those revealed in the packaging research (e.g. Yoxall et al, 2010), that is, using either physical strategies, for example using a tool such as a knife, or social strategies, for example asking a relative (see next section).

In some cases participants appeared to be proud of these solutions and were quite animated whilst explaining them. Is it possible that such problem solving could be beneficial in keeping the older mind active and in giving the user a sense of pride? The packaging study mentioned above also refers to the pride and achievement felt by users regarding their ability to solve problems (Yoxall et al, 2010). This is possibly an interesting area for further research, although the negative consequences of failing to solve a poor packaging 'puzzle' would almost certainly be greater than the gains of solving that puzzle.

\section{X4.3 Involvement of other people}

It appeared from the current study that a significant influence on the products used by older consumers comes from other people rather than the users alone. Products were often bought for them by others, or were seen being used by others, or were recommended by others. Other studies have found that people in the $76+$ age group were more likely than the younger 65-75 age group to rely on others to choose or purchase new products for them (Burrows et al, 2010).

For one participant in the current study, when her son gave her a can opener for Christmas he demonstrated to her how easy it was to use, but when she later tried to use it herself she could not use it. Therefore, an important influence on what other people buy for older users would be the perception the purchaser has of what is usable by, or will be liked by, the user - that is, what they believe makes good design for older users if they are not older users themselves. Further research amongst these purchasers would enable a greater understanding.

This study indicated that there is a family (or friend) social dynamic involved that may play an important role in the lives of older people, particularly those living alone, for example when a son or daughter is called upon to help out with problems experienced. Burrows et al (2011) also found that, given the choice, older adults often decide to involve other people in the various stages of their interaction with new technology. There may be a strong need by older people for the social interaction that these 'difficulties' bring with them, perceived or otherwise, and the authors believe, in line with Burrows et al (2011) that more understanding is required about this context. Further research might therefore be valuable to get a better understanding of this role, its implications and the extent to which product design problems and affordances 'encourage' interactions between family members or neighbours.

\section{X4.4 The effect of familiarity on purchase}

Several participants were using the same products over many years and because they were so used to the same product they would plan to buy the same one again. 
It is possible that it is more typical for the older generation than subsequent more 'disposable' generations to hold on to products for as long as possible. As a result of looking for this familiarity with what they already know, it is possible that older people may avoid innovative designs. This poses a challenge for designers: what can they do to ease the transition for these older users from their very familiar products to the unfamiliar, newer product interfaces? Previous experience with similar products is a strong predictor of usability, and those products that help the user make a reference to the same function on another more familiar device should perform better than those that do not (Lewis et al, 2006; Langdon et al, 2007). Furthermore, what innovators see as providing personal benefit may not be seen as such by the older person. The same can be said by the family of an older personif a family member purchases a new product to replace the old, worn out one, the older person may have preferred to 'battle on', rather than change the way they do things. How do we encourage users to 'battle on' with the new product long enough to recognise the benefits?

\section{X4.5 Expectations}

There was some indication from the interviews that, amongst this older generation, expectations for products to work perfectly are low. In addition, a few participants were quite accepting of the fact that in some instances they would not be able to understand how to use the products: "Why should we get our knickers in a twist because we can't understand everything that's modern?" Having to find alternatives or make adaptations in such situations does not appear to be troublesome for many participants. One possible explanation is that the older generation are used to having to 'make do' and to adapt existing products to make them usable and to last.

However, the Baby Boomer generation are just about to enter the $65+$ 'older user' category. They are considered to have two distinctive characteristics, individualism and liberalism, which are likely to affect their attitudes to products and product design (Huber and Skidmore, 2003). Compared with the previous generation, that is the current 'older users', they may be more likely to complain about products and to expect their individual wants and desires to be satisfied. Whilst the older participants in the interviews appeared to be more accepting of design problems, the younger-old are likely to be less tolerant, more demanding and therefore more likely to complain when they have problems.

\section{X.5 Conclusions and recommendations}

Despite the volume of research conducted on product usability and accessibility, results from the current study into what makes good design for older users would indicate that the basic functional needs are in fact still not being met for this user group. In particular, older people are experiencing difficulties with ease of use, packaging and weight of products. As explained by Maslow's hierarchy of needs, 
the lower level, basic needs have to be addressed before users' higher level emotional needs can be met. Therefore, the belief that appears to exist from the literature review, that the focus for product design needs to move away from the basics to the more emotional aspects of product design, would not yet appear to be advisable when considering older users. The recommendation is for designers to continue to focus on the basics of accessibility and usability of mainstream products for older users, but designs should of course aim to excel in both function and desirability.

A number of other key themes emerged from this study as possibly warranting further investigation. There was some indication that the solutions the users had to find in overcoming difficulties getting into product packaging were giving them a sense of pride. Further research might be useful in gaining a greater understanding of the value of this problem-solving for older users, the possible benefits for keeping the older mind active and the implications for product design.

In many cases, other people such as friends or relatives are purchasing everyday products for older users. It might therefore be useful to get a greater understanding of what the purchasers think is good design for the users for whom they are buying, particularly when they may be significantly younger than the users themselves. Another aspect relating to other people is the social dynamic that exists when others are purchasing products for older people, or are called upon to assist them with the products they use. Further research might be useful to understand the role such situations play in instigating social interactions and the importance these have in older people's lives.

Another key theme identified is the desire by many older users to buy products with which they are already familiar. Further research might help understand the extent to which this might hinder their acceptance of innovation and what designers can do to minimise this conflict.

However, the most important message from the current study is that the fundamental need to get the basics right for older users will be increasingly critical as the current Baby Boomer generation are beginning to enter the 'over 65' category. Compared to the current group of older users they are likely to be more demanding, less tolerant and more prone to complain about any shortfall in product design, whether in functionality or style, in meeting their needs and aspirations.

\section{X.6 References}

Baumers S and Heylighen A (2010) Harnessing different dimensions of space: the built environment in auti-biographies. In: Langdon PM, Clarkson PJ, Robinson P (eds.) Designing Inclusive Interactions. Springer, London, 13-23

Burrows A, Mitchell V, Nicolle CA (2010) Out-of-box experiences: an opportunity for inclusive design. In: Proceedings of 5th Cambridge Workshop on Universal Access and Assistive Technology, Cambridge, UK, 199-206

Burrows A, Mitchell V, Nicolle C (2011) Designing in social benefits. In: Proceedings of Include 2011, Helen Hamlyn Centre for Design, Royal College of Art, London 
Cassim J, Coleman R, Clarkson J, Dong H (2007) Why inclusive design? In: Coleman R, Clarkson J, Dong H, Cassim J (eds.) Design for Inclusivity. Gower Publishing, Aldershot, 11-21

Coleman R, Topalian A, Clarkson J, Dong H (2007) The business case. In: Coleman R, Clarkson J, Dong H, Cassim J (eds.) Design for Inclusivity. Gower Publishing, Aldershot, 33-55

Crilly N, Moultrie J, Clarkson PJ (2004) Seeing things: consumer response to the visual domain in product design. Design Studies 25: 547-577

Demirbilek O, Sener B (2003) Product design, semantics and emotional response. Ergonomics 46: 1346-1360

Engineering Design Centre (EDC), University of Cambridge (2011) Inclusive Design Toolkit at www.inclusivedesigntoolkit.com (accessed July 2011)

Heylighen A, Bianchin M (2010) Can crap design be inclusive? The case for deliberative design. In: Proceedings of 5th Cambridge Workshop on Universal Access and Assistive Technology, Cambridge, UK, 55-65

Huber J, Skidmore P (2003) The new old. Why baby boomers won't be pensioned off. DEMOS, London

Jordan PW (2000) Designing pleasurable products. Taylor \& Francis, London

Keates S, Clarkson J (2003) Design exclusion. In: Clarkson J, Coleman R, Keates S, and Lebbon C (eds.) Inclusive Design: Design for the Whole Population. Springer, London, 88-102

Langdon P, Lewis T, Clarkson J (2007) The effects of prior experience on the use of consumer products. Universal Access in the Information Society 6: 179-191

Lee Y (2010) Development of the social implications of inclusive design and some thoughts on the next steps. In: Proceedings of 5th Cambridge Workshop on Universal Access and Assistive Technology, Cambridge, UK, 27-36

Lewis T, Langdon PM, Clarkson, PJ (2006) Investigating the role of experience in the use of consumer products. In: Clarkson J, Langdon P, Robinson P (eds.) Designing Accessible Technology. Springer, London, 189-198

Maslow AH (1987) Motivation and personality, 3rd ed. revised by R Frager et al. AddisonWesley Educational Publishers, New York

Noonan T (2007) The overlooked consumer, a discussion paper examining the access, challenges and emerging possibilities for consumer electronics and home appliances. Australian Human Rights Commission

Norman DA (2004) Emotional design. Basic Books, New York

Pullin G (2009) Design meets disability. MIT Press, Boston

Yoxall A, Langley J, Musselwhite EM, Rodriguez-Falcon EM, Rowson J (2010) Husband, daughter, son and postman, hot-water, knife and towel: assistive strategies for jar opening. In: Langdon PM, Clarkson PJ, Robinson P (eds.) Designing Inclusive Interactions. Springer, London, 187-196 